\title{
FAKTOR RISIKO KEJADIAN SCABIES DI PONDOK PESANTREN NURUL ISLAM JEMBER (SCABIES RISK FACTORS IN PONDOK PESANTREN NURUL ISLAM JEMBER)
}

\author{
${ }^{1}$ Novita Nuraini, ${ }^{2}$ Rossalina Adi Wijayanti \\ ${ }^{1,2}$ Program Studi Rekam Medik Jurusan Kesehatan Politeknik Negeri Jember \\ Jalan Mastrip Kotak Pos 164 Jember \\ dr.noviatanuraini@gmail.com
}

\begin{abstract}
Abstrak
Scabies masih menjadi masalah kesehatan terutama di lingkungan padat penghuni seperti pondok pesantren. Karakteristik santri merupakan salah satu penyebab kejadian Scabies. Penelitian ini bertujuan untuk mengetahui hubungan jenis kelamin dan tingkat pendidikan dengan kejadian Skabies di Pondok Pesantren Nurul Islam Jember. Penelitian ini menggunakan metode observasional analitik dengan desain crosssectional. Sampel yang diambil dalam penelitian ini adalah seluruh populasi dengan metode proportional sampling berjumlah 56 santri dan pengambilan sampel dilakukan pada bulan Juli 2017. Variabel dalam penelitian ini terdiri dari jenis kelamin, tingkat pengetahuan dan kejadian Skabies. Diagnosis Skabies berdasarkan anamnesis dan pemeriksaan dermatologi untuk menegakkan diagnosis skabies oleh dokter peneliti. Data yang diperoleh diolah dengan software pengolahan data dan dianalisis menggunakan uji chi square. Hasil penelitian menunjukkan santri pondok pesantren nurul islam sebagian besar berjenis kelamin perempuan (56,3\%). Tingkat pengetahuan santri terkait PHBS mayoritas tergolong dalam pengetahuan kurang yaitu $73,2 \%$. Status kesehatan para santri mayoritas menderita penyakit scabies yaitu $60,3 \%$. Terdapat hubungan yang signifikan antara jenis kelamin terhadap angka kejadian skabies dengan Nilai $P$ value $=0,021$. Terdapat hubungan yang signifikan antara tingkat pengetahuan terhadap angka kejadian skabies dengan Nilai $\mathrm{P}$ value $=0$. Pencegahan Scabies lebih penting dari pengobatan salah satunya dengan penyuluhan. Agar penyuluhan kesehatan memberikan hasil yang baik, penyuluhan harus disesuaikan dengan karakteristik demografi santri antara lain jenis kelamin dan tingkat pengetahuan.
\end{abstract}

Kata kunci: jenis kelamin, tingkat pengetahuan, kejadian scabies

\begin{abstract}
Scabies is a public health problem, especially in crowded environments such as boarding schools occupants. Characteristics of students is one of the causes of the incident Scabies. This study aims to determine the relationship of gender and education level with the incidence of scabies in Pondok Pesantren Nurul Islam, Jember. This study uses observational analytic with cross-sectional design. Samples were taken in this study is the entire population by proportional sampling method amounted to 56 students, and sampling was conducted in July 2017. The variables in this study consisted of gender, level of knowledge and the incidence of scabies. Scabies Diagnosis is based on history and dermatologic examination to establish the diagnosis of scabies by the physician. The data obtained were processed with the data processing software and analyzed using chi square test. The results showed Nurul Islam boarding school students mostly female $(56.3 \%)$. The level of knowledge of students associated PHBS majority belong to the knowledge that is $73.2 \%$ less. The health status of the majority of the students suffered from scabies, namely $60.3 \%$. There is a significant relationship between sex on the incidence of scabies Rated $P$ value $=0.021$. There is a significant relationship between the level of knowledge on the incidence of scabies Rated $\mathrm{P}$ value $=0$. Scabies Prevention is more important than the treatment of one of them with counseling. Health education in order to give good results, counseling should be tailored to the demographic characteristics of students, among others, gender and level of knowledge.
\end{abstract}

Key words: gender, level of knowledge, the incidence of scabies 


\section{PENDAHULUAN}

Scabies menimbulkan ketidaknyamanan karena menimbulkan lesi yang sangat gatal. Akibatnya, penderita sering menggaruk dan mengakibatkan infeksi sekunder terutama oleh bakteri Group A Streptococci (GAS) serta Staphylococcus aureus (Golant, et al. 2012). Komplikasi akibat infestasi sekunder GAS dan S.aureus sering terjadi ada anak-anak di Negara berkembang (Golant, et al. 2012; Gilmore SJ. 2011).

Faktor yang berperan pada tingginya prevalensi skabies di negara berkembang terkait dengan kemiskinan yang diasosiasikan dengan rendahnya tingkat kebersihan, akses air yang sulit, dan kepadatan hunian (Johnstone, 2008; Roodsari, et al. 2012). Tingginya kepadatan hunian dan interaksi atau kontak fisik antar individu memudahkan transmisi dan infestasi tungau skabies. Oleh karena itu, prevalensi skabies yang tinggi umumnya ditemukan di lingkungan dengan kepadatan penghuni dan kontak interpersonal tinggi seperti penjara, panti asuhan, dan pondok pesantren (Steer, et al. 2009; Shelley, et al 2007; Roodsari, 2012).

Sebagai Negara berkembang Scabies masih menjadi masalah kesehatan di Indonesia. Prevalensi skabies di Indonesia menurut Depkes RI berdasarkan data dari puskesmas seluruh Indonesia tahun 2008 adalah 5,6\%-12,95\%. Scabies di Indonesia menduduki urutan ketiga dari 12 penyakit kulit tersering (Azizah 2011). Insiden dan prevalensi skabies masih sangat tinggi di Indonesia terutama pada lingkungan masyarakat pesantren. Hal ini diperkuat dengan penelitian Ma'rufi et al. (2005) bahwa prevalensi Scabies pada pondok pesantren di Kabupaten Lamongan 64,2\%. Kuspriyanto (2005) juga menyebutkan di Pasuruan prevalensi Scabies di pondok pesantren adalah 70\%. Selanjutnya Sungkar (1997) menyatakan bahwa Scabies di suatu pesantren yang padat penghuninya dan higienenya buruk prevalensi penderita skabies dapat mencapai $78,7 \%$, tetapi pada kelompok higienenya baik prevalensinya hanya $3,8 \%$.

Pondok pesantren adalah sekolah Islam dengan sistem asrama dan pelajarnya disebut santri. Pelajaran yang diberikan adalah pengetahuan umum dan agama tetapi dititikberatkan pada agama Islam (Haningsih, 2008). Indonesia sebagai negara dengan jumlah penduduk muslim terbanyak di dunia Tahun 2003 tercatat terdapat 14.798 pondok pesantren dengan prevalensi skabies cukup tinggi (Depkes RI, 2007). Tahun 2003, prevalensi skabies di 12 pondok pesantren di Kabupaten Lamongan mencapai 48,8\%13 dan di Pesantren AnNajach Magelang pada tahun 2008 prevalensi skabies adalah $43 \%$ (Saad, 2008). Selanjutnya Badri (2007) juga mengungkapkan bahwa Scabies merupakan penyakit yang lazim di pondok pesantren dan sejauh ini belum ada kepedulian untuk menumbuhkembangkan upaya higiene perseorangan, dalam membuat pesan-pesan kesehatan dalam mencegah skabies.

Santri yang mengidap skabies terganggu kualitas hidupnya karena keluhan gatal yang hebat serta infeksi sekunder. Keluhan tersebut menurunkan kualitas hidup dan prestasi akademik. Muzakir (2008) dalam penelitian menyebutkan sebanyak $15,5 \%$ santri penderita skabies di Provinsi Aceh menurun nilai rapornya. Sselanjutnya, Sudarsono juga menyebutkan bahwa di Medan pada tahun 2011 prestasi belajar santri menjadi lebih rendah dibandingkan sebelum menderita Scabies.

Pada dasarnya pengetahuan tentang faktor penyebab Scabies masih kurang, sehingga penyakit ini dianggap sebagai penyakit yang biasa saja karena tidak membahayakan jiwa. Masyarakat tidak mengetahui bahwa luka akibat garukan dari penderita Scabies menyebabkan infeksi sekunder dari bakteri Stapilococos sp ataupun jamur kulit yang berakibat kerusakan jaringan kulit yang akut (Heukelbach 2005). Tingkat pendidikan ternyata berhubungan dengan tingkat prevalensi Scabies. Tingkat pendidikan yang rendah (paling tinggi hanya sampai sekolah dasar) cenderung lebih tinggi prelevansi skabiesnya secara signifikan dibandingan dengan orang dengan tingkat pendidikan yang lebih tinggi (Ciftci 2006). Pendidikan memegang peranan penting dalam mencegah tingginya prevalensi Scabies, misalnya mengedukasi anak-anak tentang pengetahuan pencegahan Scabies. Contohnya himbaun untuk melarang anak untuk berbagi barang pribadi seperti baju, handuk, selimut yang menjadi agen penularan Scabies melalui kontak dari kulit ke kulit (Zayyid 2010). Semakin rendah tingkat pendidikan sesorang maka tingkat pengetahuan tentang personal higienis juga semakin rendah. Akibatnya menjadi kurang peduli tentang pentingnya personal higienis dan perannya dalam higiene rendah terhadap penyebaran penyakit. Perlu program kesehatan umum untuk mendidik populasi mengerti aspek pencegahan penyakit (Raza et al. 2009).

Penelitian Baur et al. (2013) di India dan juga Chowsidow (2006) di Inggris menunjukkan bahwa wanita cenderung memiliki prevalensi skabies yang lebih tinggi sebesar 56\% dibandingkan lakilaki. Menurut peneliti wanita memiliki tingkat prevalensi skabies yang lebih tinggi diduga disebabkan beberapa faktor seperti sikap dan perilaku wanita yang lebih senang berada dalam 
ruangan dengan kontak satu sama lain yang lebih dekat sehingga lebih rentan terinfestasi Scabies. Berbeda dengan penelitian Raharnie et al. (2011) di Makasar, Zayyid (2010) di Malaysia dan Onayemi et al. (2005) di Nigeria menunjukkan bahwa lakilaki cenderung lebih rentan terinfeksi Scabies dengan prevalensi $58 \%$ dibandingkan wanita. Prevalensi Scabies pada wanita cenderung lebih rendah dari pada laki-laki, diduga disebabkan wanita cenderung lebih peduli terhadap personal higienis dibandingkan laki-laki. Hal yang berbeda terjadi di Turki yang menunjukkan tidak ada perbedaan yang signifikan dari dua jenis kelamin laki-laki dan perempuan terhadap prevalesnsi Scabies (Citfci et al. 2006).

Hasil penelitian menunjukkan beberapa faktor penyebab Scabies. Faktor yang menyebabkan Scabies adalah keterkaitan antara faktor sosio demografi dengan lingkungan (Baur et al. 2013). Penyakit Scabies berasosiasi secara kuat dengan kemiskinan dan kepadatan penduduk (Heukelbach et al. 2006). Faktor yang mengakibatkan tinggginya prevalensi Scabies antara lain kelembaban yang tinggi, rendahnya sanitasi, kepadatan, malnutrisi (Onayemi, 2005), personal higiene yang buruk, pengetahuan, sikap dan perilaku yang kurang mendukung pola hidup sehat (Ma'rufi 2005). Baur (2013) juga melaporkan faktor personal higiene, ketersediaan air bersih, status sosial ekonomi berpengaruh terhadap prevalensi skabies di India. Rendahnya status gizi mempengaruhi sistem imun, sehingga menurunkan sistem kekebalan tubuh juga menyebabkan tingginya prevalensi skabies (Melton 1978). Kebiasaan tidur, berbagi baju, handuk, praktek hygiene yang tidak benar, sering berpergian ke tempat yang beresiko dan berpotensi sebagai sumber penularan Scabies merupakan faktor ganda yang menyebabkan Scabies (Raza et al. 2009). Sanitasi lingkungan yang buruk di merupakan faktor dominan yang berperan dalam penularan dan tingginya angka prevalensi penyakit Scabies (Ma'rufi et al. 2005).

Di Kabupaten Jember, terdapat pesantren padat penghuni dan santrinya banyak yang mengeluh kudisan. Berdasarkan beberapa hasil penelitian pencegahan penyakit skabies lebih penting dari pengobatan, sehingga menjadi tantangan bagi dunia pendidikan untuk mencari sebuah solusi untuk pencegahan penyakit yang lebih efektif. Tingkat pengetahuan merupakan salah satu faktor yang berkontribusi terhadap peningkatan prevalensi skabies sehingga diperlukan pendidikan agar populasi mengerti aspek pencegahan penyakit (Raza et al. 2009). Pencegahan penyakit skabies ini lebih efektif jika dilakukan melalui pendidikan. Pendidikan pencegahan penyakit memberikan informasi pengetahuan yang muaranya mengubah sikap dan perilaku menjadi lebih higienis sehingga mampu mencegah berbagai macam penyakit, termasuk skabies. Namun agar penyuluhan kesehatan memberikan hasil yang baik, penyuluhan harus disesuaikan dengan karakteristik demografi santri antara lain jenis kelamin dan tingkat pengetahuan. Oleh karena itu, perlu dilakukan penelitian untuk mengetahui hubungan jenis kelamin dan tingkat pengetahuan dengan kejadian Scabies di Pondok Pesantren Nurul Islam Jember.

\section{METODOLOGI}

Penelitian ini menggunakan metode observasional analitik dengan desain cross sectional. Metode ini digunakan mengetahui hubungan faktor penyebab dengan kejadian Scabies. Tujuannya agar penanganan masalah kesehatan sesuai dengan faktor penyebabnya.

Tempat dan Waktu Penelitian akan dilakukan di Pondok Pesantren Nurul Islam Jember. Alamat jalan Tawangmangu Kelurahan Antirogo Kecamatan Sumbersari Kabupaten Jember pada bulan Maret Tahun 2017.

Populasi dalam penelitian ini adalah seluruh santri di Pondok Pesantren Nurul Islam Jember. Diketahui jumlah total santri berjumlah 56 orang. Sampel yang diambil dalam penelitian ini adalah seluruh populasi dengan metode proportional sampling.

Pengumpulan data dilakukan melalui beberapa tahap, yaitu: pertama, memberikan kuisioner kepada responden yaitu santri. Kedua, melakukan anamnesis dan pemeriksaan dermatologi untuk menegakkan diagnosis skabies oleh dokter peneliti.

Hasil analisis merupakan pengolahan data kuesioner dan hasil pemeriksaan responden yang diolah dengan software pengolahan data dan dianalisis menggunakan uji chi square.

\section{HASIL DAN PEMBAHASAN}

Di Pondok Pesantren Nurul Islam Jember, santri yang menghuni ruangan depan terdapat 73 santri, namun yang diikutsertakan dalam penelitian ini adalah 56 orang karena 12 orang santri tidak hadir saat pengambilan data 5 santri tidak mengisi questioner.

\section{Identifikasi Jenis Kelamin Santri}

Berdasarkan hasil penelitian didapatkan sebaran jenis kelamin responden adalah lebih banyak santri berjenis kelamin perempuan yaitu 30 orang $(53,6 \%)$, sedangkan santri laki-laki berjumlah 26 orang $(46,4 \%)$. Prosentase jenis kelamin santri dapat dilihat pada Tabel 5.1.

Tabel 5.1 Jenis Kelamin Santri 


\begin{tabular}{|l|l|c|c|}
\hline No & Jenis Kelamin & n & $\begin{array}{c}\text { Persentase } \\
(\mathbf{\%})\end{array}$ \\
\hline 1 & Laki-laki & 26 & $46,4 \%$ \\
\hline 2 & perempuan & 30 & $53,6 \%$ \\
\hline Jumlah & 56 & $100,0 \%$ \\
\hline
\end{tabular}

\section{Identifikasi Tingkat Pengetahuan Santri}

Identifikasi tingkat pengetahuan santri dapat dilihat pada Tabel 5.2.

Tabel 5.2 Tingkat Pengetahuan Santri

\begin{tabular}{|l|l|c|c|}
\hline No & $\begin{array}{c}\text { Tingkat } \\
\text { Pengetahuan }\end{array}$ & n & $\begin{array}{c}\text { Persentase } \\
(\%)\end{array}$ \\
\hline 1 & kurang & 41 & $73,2 \%$ \\
\hline 2 & baik & 15 & $26,8 \%$ \\
\hline Jumlah & 56 & $100,0 \%$ \\
\hline
\end{tabular}

Identifikasi tingkat pengetahuan santri didapatkan melalui penyebaran questioner yang berisi pertanyaan 10 pertanyaan terkait dengan pengetahuan PHBS di pondok pesantren. Para santri diminta untuk mengisi jawaban kemudian peneliti menilai dan memberikan skor.kemudian dari skor yang didapatkan menimbulkan interpretasi pembagian tingkat pengetahuan santri menjadi pengetahuan kurang dan pengetahuan baik dengan pengkategorian sebagai berikut:

a. Kategori tingkat pengetahuan

b. Baik, bila $X>$ median $(X>9.0)$

c. Kurang, bila $X<$ median $(X<9.0)$

Berdasarkan tabel diatas menunjukkan sebagian besar santri memiliki tingkat pengetahuan terhadap PHBS kurang yaitu 41 santri $(73,2 \%)$ sedangkan santri yang memiliki tingkat pengetahuan baik hanya berjumlah 15 orang $(26,8$ $\%)$.

\section{Identifikasi Kejadian Scabies Pada Santri}

Hasil identifikasi kejadian scabies pada santri dapat dilihat pada Tabel 5.3.

Tabel 5.3 Kejadian Scabies Pada Santri

\begin{tabular}{|l|l|c|c|}
\hline No & \multicolumn{1}{|c|}{$\begin{array}{c}\text { Kejadian } \\
\text { Scabies }\end{array}$} & n & $\begin{array}{c}\text { Persentase } \\
(\mathbf{\%})\end{array}$ \\
\hline 1 & scabies & 34 & $60,7 \%$ \\
\hline 2 & Tidak scabies & 22 & $39,3 \%$ \\
\hline Jumlah & 56 & $100,0 \%$ \\
\hline
\end{tabular}

Penelitian ini dilakukan dengan cara dokter peneliti melakukan anamnesis serta pemeriksaan dermatologi kepada seluruh santri. Hasil penelitian didapatkan sebagian besar santri menderita penyakit scabies yaitu berjumlah 34 santri $(60,7 \%)$, sedangkan yang tidak menderitaa penyakit scabies berjumlah 22 santri (39,3\%). Diagnosis scabies didapat melalui tanda dan gejala berupa rasa gatal yang sangat dan terutama memburuk saat malam hari, timbulnya terowongan kecil dengan benjolan kecil di ujungnya pada kulit, menyerang sela jari kaki, sela jari tangan, bokong, sekitar organ intim, punggung, jika digaruk akan mengeluarkan cairan bening yang bisa menyebarkan rasa gatal pada tempat lain, serta biasa menyerang an menular dengan orang terdekat yang sering kontak kulit.

\section{Hubungan Jenis Kelamin Dengan Kejadian Scabies Santri}

Dalam penelitian ini, dilakukan uji statistik untuk mengetahui hubungan antara jenis kelamin dengan prevalensi skabies menggunakan Uji chi square. Dimana menunjukkan ada hubungan antara jenis kelamin dengan prevalensi scabies. Pada santri laki-laki lebih banyak menderita skabies. Hal tersebut kemungkinan disebabkan santri perempuan lebih memperhatikan kesehatan kulit dibandingkan santri laki-laki

Hasil penelitian ini menunjukkan bahwa prevalensi skabies berhubungan dengan jenis kelamin yaitu Nilai $\mathrm{P}$ value $=0,021$ dengan nilai alpha $=0,05$. Prevalensi penyakit skabies lebih tinggi pada laki-laki. Hasil penelitian ini sesuai dengan laporan Khobir yang menyatakan bahwa di pesantren di daerah Pekalongan didapatkan bahwa prevalensi skabies pada laki-laki lebih tinggi daripada perempuan. Khobir menyatakan hal tersebut mungkin karena santri perempuan lebih memperhatikan kebersihan diri. Penelitian oleh Fakoorziba, et al di Iran juga menunjukkan prevalensi skabies tertinggi terdapat pada lakilaki. Penelitian oleh Shawa di Gaza pada tahun 2005 menunjukkan prevalensi skabies sedikit lebih tinggi pada laki-laki, yaitu 57\%, dibandingkan pada perempuan yaitu $43 \%$.

\section{Hubungan Tingkat Pengetahuan Dengan Kejadian Scabies Santri}

Dalam penelitian ini, dilakukan uji statistik untuk mengetahui hubungan antara tingkat pengetahuan santri dengan prevalensi skabies menggunakan Uji chi square. Dimana menunjukkan ada hubungan yang signifikan antara tingkat pengetahuan santri terhadap PHBS dengan prevalensi scabies. Sebagian besar santri yang menderita scabies menunjukkan hasil pengetahuannya kurang terhadap PHBS pondok pesantren yaitu 33 santri sedangkan hanya 1 santri yang menderita scabies namun memiliki pengetahuan baik. Hal tersebut kemungkinan disebabkan santri dengan pengetahuan PHBS yang baik telah mengadopsi PHBS di dalam kegiatannya sehari-hari sehingga terhindar dari penularan scabies.

Hasil penelitian ini menunjukkan bahwa prevalensi skabies berhubungan dengan tingkat pengetahuan dengan Nilai $\mathrm{P}$ value $=0,000$ dengan nilai alpha $=0,05$. Prevalensi penyakit skabies lebih tinggi pada santri dengan tingkat 
pengetahuan kurang. Hasil penelitian ini sesuai dengan pernyataan Ma'rufi, 2005 bahwa faktor yang mengakibatkan tinggginya prevalensi Scabies antara lain kelembaban yang tinggi, rendahnya sanitasi, kepadatan, malnutrisi (Onayemi, 2005), personal higiene yang buruk, pengetahuan, sikap dan perilaku yang kurang mendukung pola hidup sehat

\section{KESIMPULAN}

Berdasarkan hasil penelitian hubungan jenis kelamin dan tingkat pegetahuan dengan kejadian skabies di pondok pesantren nurul islam jember dapat ditarik kesimpulan sebagai berikut:

a. Sebagian besar santri berjenis kelamin perempuan yaitu $56,3 \%$.

b. Tingkat pengetahuan santri terkait PHBS mayoritas tergolong dalam pengetahuan kurang yaitu $73,2 \%$.

c. Sebagian besar santri menderita penyakit scabies yaitu $60,3 \%$.

d. Terdapat hubungan yang signifikan antara jenis kelamin santri terhadap angka kejadian scabies

e. Terdapat hubungan yang signifikan antara tingkat pengetahuan santri terhadap angka kejadian scabies

Sasaran penanggulangan penyakit PHBS di pondok pesantren nurul islam sebaiknya lebih diutamakan pada kelompok santri laki-laki serta melalui metode-metode dengan tujuan peningkatan pengetahuan santri mengenai $\mathrm{PHBS}$

\section{UCAPAN TERIMA KASIH}

Tim penelitian mengucapkan terima kasih kepada Pondok Pesantren Nurul Islam Jember dan Politenik Negeri Jember atas dukungan pendanaan sehingga kegiatan ini dapat terlaksana dengan baik. Kegiatan penelitian ini menjadi salah satu bentuk implemetasi Politeknik Negeri Jember untuk dapat mengatasi masalah yang sedang dihadapi. Kegiatan Penelitian dilaksanakan di Pondok Pesantren Nurul Islam Jember dalam upaya pencegahan masalah kesehatan.

\section{DAFTAR PUSTAKA}

Azizah I.N. \& Setiyowati W. (2011). Hubungan tingkat pengetahuan ibu pemulung tentang personal hygiene dengan kejadian skabies pada balita di tempat pembuangan akhir kota semarang. Dinamika Kebidanan 1, 1-5.

Badri M. 2007. Hygiene perseorangan santri pondok pesantren wali songo ngabar ponorogo. Media Litbang Kesehatan 17, 1-7.
Baur B., Sarkar J.,Manna N., \& Bandyopadhyay L. (2013). The Pattern of Dermatological Disorders among Patients Attending the Skin O.P.D of A Tertiary Care Hospital in Kolkata, India. Journal of Dental and Medical Sciences 3, 1-6.

Chowsidow. 2006. Skabies. The new england journal of medicine. 35,1-16

Ciftci IK, Karaca S, Dogru O, Cetinkaya Z, \& Kulac K. (2006). Prevalence of pediculosis and skabies in preschool nursery children of Afyon, Turkey. Korean Journal of Parasitology 44, 95-98

Depkes RI, 2007). Pedoman penyelenggaraan dan pembinaan pos kesehatan pesantren. 2007. Diunduh dari: http://perpustakaan.depkes.go.id.

Gilmore SJ. Control strategies for endemic childhood scabies. PloS One. 2011;6:e15990.

Golant AK, Levitt JO. Scabies: a review of diagnosis and management based on mite biology. Pediatr Rev.2012;33:e1-e12.

Haningsih S. Peran strategis pesantren, madrasah, dan sekokah Islam di Indonesia. El Tarbawi Jurnal Pendidikan Islam. 2008;1:1.

Heukelbach J, Wilcke T, Winter B \& Feldmeier. (2005). Epidemiology and morbidity of scabies and pediculosis capitis in resourcepoor communities in Brazil. British Journal of Dermatology 153:150-156.

Johnstone P, Strong M. Scabies. BMJ. 2008;8:1707.

Kline K., James S. McCarthy, Pearson M, Loukas A., \& Hotez P. (2013). Neglected tropical diseases of oceania: review of their prevalence, distribution, and opportunities for control. Plosneglected tropical diseases, 7, 17-55.

Kuspriyanto (2005). Pengaruh sanitasi dan higiene perorangan terhadap penyakit kulit. Tesis tidak diterbitkan. Surabaya: PPs Universitas Airlangga.

Ma'rufi I, Keman S, \& Notobroto HB. (2005). Faktor sanitasi lingkungan yang berperan terhadap prevalensi penyakit skabies studi pada santri di pondok pesantren kabupaten Lamongan. Jurnal kesehatan lingkungan 2, 11 -18 . 